\title{
P fimbriation among biochemically inactive strains of Escherichia coli of the group formerly called Alkalescens-Dispar
}

\author{
D. C. OLD and PAMELA B. CRICHTON
}

\section{Department of Medical Microbiology, Dundee University Medical School, Ninewells Hospital, Dundee DD1 9SY}

\begin{abstract}
Summary. Biochemically inactive, non-motile strains of Escherichia coli of the group formerly known as Alkalescens-Dispar (AD) and of known AD serogroups were analysed for biotype, resistotype, type-1 fimbriation, $\mathrm{P}$ fimbriation and haemolysin production. All strains of $A D$ serogroups $\mathrm{O} 1$ and $\mathrm{O} 2$ examined were $\mathrm{P}$-fimbriate and of closely related bio-resistotypes, suggesting that they may be representatives of two $E$. coli P-fimbriate clones, members of which have not infrequently been isolated from infected urine.
\end{abstract}

\section{Introduction}

Among uropathogenic strains of Escherichia coli, the property of $\mathrm{P}$ fimbriation correlates significantly with the ability to produce pyelonephritis (Källenius et al., 1981; Väisänen-Rhen et al., 1984). $\mathrm{P}$ fimbriae recognise specifically a minimal receptor structure $\alpha$-D-Gal-(1-4)- $\beta$-D-Gal, a part of the glycosphingolipids related to the $\mathrm{P}$ blood-group antigens of human erythrocytes (Källenius et al., 1980a). Although generally described as agglutinating human erythrocytes only (Källenius and Möllby, 1979), the majority of P-fimbriate $E$. coli strains, when tested at appropriate concentration, give mannose-resistant and eluting (MRE) haemagglutination of the erythrocytes of man, pig and sheep, i.e., their haemagglutination pattern is MPS (Old et al., 1980; Old, 1985).

We have previously reported (Crichton et al., 1981) that tests for the presence of MRE haemagglutinins (HAs) are helpful in differentiating biochemically inactive strains of $E$. coli of the Alkalescens-Dispar (AD) group from shigellae, which they mimic in many routine diagnostic characters. Thus, many AD bacteria $(65 \%)$ produce MREHAs of the MPS or related haemagglutination patterns (Crichton et al., 1981). In view of the suggestion that $\mathrm{AD}$ bacteria may be opportunist pathogens of the urinary tract (Kauffman, 1969), it is of interest that all strains of AD serogroups $\mathrm{Ol}$ and $\mathrm{O} 2$ are $\mathrm{P}$ fimbriate.

Received 19 Jul. 1985; accepted 12 Aug. 1985.

\section{Materials and methods}

\section{Bacterial strains}

Of the $42 \mathrm{AD}$ strains of $E$. coli examined, 40 were described by Crichton et al. (1981); the other two strains were recent isolates from our own laboratory. Most (18 strains) belonged to the commonest AD serogroup O1 (Frantzen, 1950); six strains were either non-serotypable (NST) or autoagglutinating. The other strains belonged to seven AD serogroups: O2 (4 strains), O3 (4), O4 (4), O5 (3), O6 (1), O7 (1) and O8 (1). Of the 22 strains of serogroups $\mathrm{O} 1$ and $\mathrm{O} 2$, only two from the original collection of Kauffmann (1969) had not been examined to verify the absence of $\mathrm{H}$ antigen (Drs F. and I. Orskov, personal communication).

\section{Media}

Nutrient Broth No. 2 and Nutrient Agar (CM3) were obtained from Oxoid. Phosphate-buffered broth (PBB) and phosphate-buffered agar (PBA) were, respectively, nutrient broth and nutrient agar with $\mathrm{KH}_{2} \mathrm{PO}_{4} 0.35 \% \mathrm{w} / \mathrm{v}$ and $\mathrm{Na}_{2} \mathrm{HPO}_{4} 0.65 \% \mathrm{w} / \mathrm{v}(p \mathrm{H} 7 \cdot 0)$.

\section{Production and detection of haemagglutinins}

For the production of type-1 fimbriae and mannosesensitive (MS) HA, bacteria were grown serially in nutrient broth $(10 \mathrm{ml})$ in cotton-wool stoppered test tubes incubated statically at $37^{\circ} \mathrm{C}$ for $48 \mathrm{~h}$. A strain was designated as MSHA-negative if it gave a negative MSHA result in each of six serial broth cultures (Duguid et al., 1979). For MREHA, strains were grown at $37^{\circ} \mathrm{C}$ either on PBA ( $20 \mathrm{ml} / 9-\mathrm{cm}$ plate) for $24 \mathrm{~h}$ or in PBB (10 $\mathrm{ml}$ ) for $48 \mathrm{~h}$ (Duguid et al., 1979; Crichton, 1980). 
Bacterial suspensions containing $c$. $(5-10) \times 10^{10} \mathrm{cfu} / \mathrm{ml}$ for MSHA tests and $1 \times 10^{12} \mathrm{cfu} / \mathrm{ml}$ for MREHA tests were prepared as described previously (Duguid et al., 1979; Old, 1985). Suspensions were mixed on a porcelain tile in the presence and absence of $\alpha$-methyl-mannoside with the following erythrocyte species: fowl $(F)$, guinea pig $(\mathrm{G})$, horse $(\mathrm{H})$, human, group $\mathrm{O}(\mathrm{M})$, ox $(\mathrm{O})$, pig $(\mathrm{P})$ and sheep $(\mathrm{S})$. Tiles were rocked at room temperature $(c$. $20^{\circ} \mathrm{C}$ ) or at $4^{\circ} \mathrm{C}$ for $15 \mathrm{~min}$. Cultures producing MSHA agglutinated, for example, guinea-pig erythrocytes at both low and high temperatures but only in the absence of $\alpha$-methyl-mannoside; cultures producing MREHA agglutinated erythrocytes in the presence and absence of $\alpha$ methyl-mannoside but did so better at lower than at higher temperatures and eluted from the erythrocytes when the temperature of the mixture was raised to $\leqslant 50^{\circ} \mathrm{C}$ by gentle warming of the tile.

Furthermore, suspensions were tested with human erythrocytes of the rare $\overline{\mathbf{p}}$ phenotype. Any strain that agglutinated human erythrocytes of $P_{1}$ or $P_{2}$ phenotypes but not those of the $\overline{\mathbf{p}}$ phenotype in MRE fashion was designated $\mathrm{P}$ fimbriate (Källenius et al., 1981; Väisänen et al., 1981).

Hydatid-cyst fluid (HCF) from sheep or tissue-cultures infected with Echinococcus granulosum contains $\mathrm{P}_{1}$ substance, a natural analogue of the glycoprotein receptor of P fimbriae (Parry et al., 1984). Rocked-tile tests were performed as before, except that bacterial suspensions, tested neat and at dilutions of 1 in 5 and 1 in 10 , were preincubated with $\alpha$-methyl-mannoside and HCF for $30 \mathrm{~min}$ at $4^{\circ} \mathrm{C}$ before addition of erythrocytes (Parry et al., 1984). The ability of HCF to inhibit MRE haemagglutination of human erythrocytes of $P_{1}$ or $P_{2}$ phenotype indicated the presence of $P$ fimbriae (Parry et al., 1984).

\section{Haemolysin production}

The ability of strains to form haemolysin was tested on plates of sheep-blood agar. They were examined for zones of clearing around isolated colonies after overnight incubation at $37^{\circ} \mathrm{C}$.

\section{Biotyping}

AD strains of $E$. coli were biotyped by the two-tier scheme of Crichton and Old (1982). Strains were assigned to one of 16 primary biotypes on the basis of their reactions in tests with: raffinose (Raf), sorbose (Sor), ornithine (Orn) and dulcitol (Dul). Further discrimination was afforded by results in seven other secondary tests: rhamnose (Rha), lysine (Lys), aesculin (Aes), motility (Mot), type-1 fimbriation (Fim), 5-ketogluconate $(\mathrm{Kgl})$ and prototrophy (Pro). Full details of the tests and their interpretation have been reported elsewhere (Crichton and Old, 1979, 1982 and 1985).

\section{Resistotyping}

Chemicals used in resistotyping tests were: A, sodium arsenate; $B$, phenylmercuric nitrate; $C, 4-4^{\prime}$ diamidinodiphenylamine dihydrochloride; $\mathrm{D}$, boric acid; $\mathrm{E}$, acriflavine; F, 4-chlororesorcinol; G, cupric sulphate; and H, malachite green. Details of the method used, a modification of that originally developed by Elek and Higney (1970), have been published previously (Old et al., 1980; Wilson et al., 1981; Crichton and Old, 1983). The basis of the technique is the selective toxicity to strains of $E$. coli of these eight chemicals, each tested at a critical concentration in agar. On every occasion of testing, each chemical was tested at a narrow range of concentration around the optimum. The use of five reference strains on each plate with 20 test strains clearly showed the plate containing the concentration of chemical giving the expected growth pattern of the reference strains. From that plate, results for the test strains were read, thus ensuring their optimal type differentiation. Resistotypes were assigned as before (Wilson et al., 1981): a strain of resistotype pattern AcDEF was resistant to chemicals $A, D, E$ and $F$, partially resistant to chemical $C$ and sensitive to chemicals $B, G$ and $H$. When tested on the same plate, the resistotype pattern of different isolates of a strain is reproducible differing in one or, rarely, two minor characteristics (Elek and Higney, 1970; Old et al., 1980). Thus, resistotypes acDEF, aCDEF and aCDeF would suggest strain identity.

\section{Serological tests}

Antisera were prepared in rabbits (Adegbola and Old, 1982) against authentic P-fimbriate $E$. coli strains ER2 and JR1 obtained from Dr G. Källenius. O, type-1 fimbrial and, for strain ER2, $H$ antibodies were removed from each crude antiserum by appropriate absorptions to give pure P-fimbrial antisera which reacted to titres of 2560 and 5120 , respectively, in tube-agglutination tests with homologous strains. All P-fimbriate AD strains of groups $\mathrm{O} 1$ and $\mathrm{O} 2$ were examined for agglutination in slide tests and several unselected strains were tested by tube agglutination. Type-1 fimbrial antiserum against $E$. coli strain A108 was available from another study (Crichton et al., 1981).

\section{Results}

\section{Adhesins}

Among the 42 AD strains, $28(67 \%)$ produced MREHAs of one of three different haemagglutination patterns: 24 strains produced MREHA of pattern MPS; three strains produced MREHA of pattern GMPS (the additional reactivity with guinea-pig cells, though weak, was constant); and one strain produced a narrow-spectrum MREHA reacting with human erythrocytes only of the seven species tested (table I). Furthermore, the haemagglutination of erythrocytes of man (or pig or sheep or guinea pig) by strains producing MREHA 
Table I. Distribution of MSHA, MREHA and P fimbriation among biochemically inactive AD strains of $E$. coli

\begin{tabular}{|c|c|c|c|c|c|c|c|}
\hline \multirow{2}{*}{$\begin{array}{l}\text { AD } \\
\text { O sero- } \\
\text { group }\end{array}$} & \multicolumn{3}{|c|}{ Number of strains } & \multirow{2}{*}{$\begin{array}{l}\text { MREHA } \\
\text { pattern } \\
\text { (number of } \\
\text { strains) }\end{array}$} & \multicolumn{2}{|c|}{$\begin{array}{c}\text { HA of human } \\
\text { erythrocytes } \\
\text { of phenotype }\end{array}$} & \multirow{2}{*}{$\begin{array}{l}\text { Inhibition of } \\
\text { HA by HCF } \\
\text { (P fimbriation) }\end{array}$} \\
\hline & tested & $\mathrm{MSHA}^{+}$ & MREHA $^{+}$ & & $\mathbf{P}_{1}, \mathbf{P}_{2}$ & $\overline{\mathbf{p}}$ & \\
\hline \multirow{2}{*}{1} & \multirow{2}{*}{18} & \multirow{2}{*}{2} & \multirow{2}{*}{18} & MPS (16) & + & - & + \\
\hline & & & & I GMPS (2) & + & - & + \\
\hline 2 & 4 & 1 & 4 & MPS (4) & + & - & + \\
\hline 3 & 4 & 2 & 0 & $\ldots$ & $\ldots$ & $\ldots$ & $\ldots$ \\
\hline 4 & 4 & 0 & 0 & & $\ldots$ & $\ldots$ & $\ldots$ \\
\hline 5 & 3 & 0 & 1 & M (1) & + & + & - \\
\hline 6 & 1 & 0 & 0 & & $\ldots$ & $\ldots$ & $\ldots$ \\
\hline 7 & 1 & 1 & 1 & MPS (1) & + & - & + \\
\hline 8 & 1 & 0 & 0 & $\ldots$ & $\ldots$ & $\ldots$ & $\ldots$ \\
\hline NST & 1 & 1 & 0 & $\ldots$ & $\ldots$ & $\ldots$ & $\ldots$ \\
\hline AA & 5 & 0 & 4 & $\left\{\begin{array}{l}\text { MPS (3) } \\
\text { GMPS (1) }\end{array}\right.$ & $\begin{array}{l}t \\
t\end{array}$ & - & $\begin{array}{l}+ \\
+\end{array}$ \\
\hline
\end{tabular}

$\mathrm{NST}=$ Non-serotypable; $\mathrm{AA}=$ autoagglutinating $\mathrm{HCF}=$ hydatid-cyst fluid; $\ldots=$ not applicable.

of patterns MPS or GMPS was inhibited by hydatid-cyst fluid (HCF) suggesting that these two haemagglutination patterns were associated with $\mathrm{P}$ fimbriae. The narrow-spectrum MREHA (pattern M) of the strain of serogroup O5 reacted with human erythrocytes only, including those of the $\bar{p}$ type; that activity was not inhibited by HCF and it was not, therefore, associated with $P$ fimbriae. Indeed, that kind of MREHA (pattern 9 of Duguid et al., 1979) is associated with either glycocalyx or fibrillar proteinaceous capsule (Williams et al., 1984; Ørskov et al., 1985). Our reporting of MREHA-type $M$, according to the terminology used by Old et al. (1980), should not be confused with the blood-group M-specific HA of glycophorin A subsequently described by Väisänen et al. (1982).

Whereas all strains of serogroups $\mathrm{O} 1$ and $\mathrm{O} 2$ were $P$ fimbriate, only one strain of serogroups $\mathrm{O} 3-8$ and NST was P fimbriate (table I). Again, four of five rough, autoagglutinable strains were $P$ fimbriate (MREHAs of patterns MPS or GMPS). Thus, the association of $P$ fimbriation with $A D$ serogroups $\mathrm{O} 1$ and $\mathrm{O} 2$ was high.

The P-fimbriate AD strains reacted only to a moderate, or low, titre $(\leqslant 640)$ in tube agglutination tests with P-fimbrial antisera against $E$. coli strains ER2 or JR1 and the agglutination reaction was weak (14 strains) or undetectable (13) in tests made on glass slides.

Only seven ( $17 \%$ ) of the 42 AD strains formed MSHA in serial broth cultures and production of MSHA was as uncommon among P-fimbriate strains of serogroups $\mathrm{O} 1$ and $\mathrm{O} 2$ as among other AD strains (table I). MSHA production was associated with type-1 fimbriae serologically related to those of E. coli strain A108.

\section{Biotypes and resistotypes}

All 18 strains of $\mathrm{AD}$ serogroup $\mathrm{O} 1$ belonged to primary biotype $11\left(\mathrm{Raf}^{-} \mathrm{Sor}^{+} \mathrm{Orn}^{-} \mathrm{Dul}^{+}\right)$. Twelve strains were of full biotype 11 bdef (indicating negative results in the secondary tests for Rha, Aes, Mot and Fim, symbols ' $b$ ', 'd', 'e' and 'f', respectively). Three $\mathrm{Lys}^{-}$strains (full biotype $11 \mathrm{bcdef}$ ), two type-1 fimbriate strains (full biotype $11 \mathrm{bde}$ ) and one strain that did not ferment 5-ketogluconate (full biotype 11 bdefg) differed from the majority cluster in only one marker each (table II). In addition, their resistotypes (table II) fulfilled the criteria suggestive of strain identity: three (ADeFH, AcdeFH and acDeFH) differed from the majority resistotype $\mathrm{AcDeFH}$ in only one minor character and one (acDFH) in two minor characters.

All four strains of serogroup $\mathrm{O} 2$ belonged to primary biotype $16\left(\mathrm{Raf}^{-} \mathrm{Sor}^{-} \mathrm{Orn}^{-} \mathrm{Dul}^{-}\right)$; two strains were of full biotype 16bdefg (indicating negative results in secondary tests for Rha, Aes, Mot, Fim and $\mathrm{Kgl}$ ); two Lys ${ }^{-}$strains were similar in their secondary biotype characters (negative in Rha, Lys, Aes, Mot and $\mathrm{Kgl}$ ) except that one was type-1 fimbriate (biotype 16bcdeg) and the other was type-1 non-fimbriate (biotype 16bcdefg) (table II). These four strains were of closely related 
Table II. Biotype and resistotype profiles of Pfimbriate AD strains of $E$. coli

\begin{tabular}{lccc}
\hline $\begin{array}{c}\text { AD } \\
\text { O sero- } \\
\text { group }\end{array}$ & $\begin{array}{c}\text { Primary } \\
\text { biotype* }\end{array}$ & $\begin{array}{c}\text { Full } \\
\text { biotype* } \\
\text { (number } \\
\text { of strains) }\end{array}$ & Resisotype† \\
\hline 1 & $11(18)$ & $\begin{array}{l}\text { l1bdef (12) } \\
11 \text { bcdef (3) } \\
11 \text { bde (2) } \\
11 \text { bdefg (1) }\end{array}$ & $\begin{array}{l}\text { AcDeFH (13) } \\
\text { acDFH (1) } \\
\text { ADeFH (1) } \\
\text { AcdeFH (1) } \\
\text { acDeFH (2) }\end{array}$ \\
2 & $16(4)$ & $\left\{\begin{array}{l}16 \text { bdefg (2) } \\
16 \text { bcdeg (1) } \\
16 \text { bcdefg (1) } \\
7 \text { bde (1) }\end{array}\right.$ & $\left\{\begin{array}{l}\text { ADEF (3) } \\
\text { AdEF (1) }\end{array}\right.$ \\
AcDEF (1) \\
AA & $11(4)$ & $\left\{\begin{array}{l}11 \text { bdef (3) } \\
11 \text { bcdef (1) }\end{array}\right.$ & $\begin{array}{l}\text { AcdeFH (1) } \\
\text { AcDeFH (2) } \\
\text { acDeFH (1) }\end{array}$
\end{tabular}

$\mathrm{AA}=$ autoagglutinating.

* See Crichton and Old (1982 and 1985).

$\dagger$ See Crichton and Old (1983).

resistotypes (ADEF and AdEF) each differing from the majority pattern of $\mathrm{Ol}$ strains in both a minor (c) and a major $(\mathrm{H})$ character.

Of the other five P-fimbriate strains, one strain of serogroup 07 was of biotype 7 bde and resistotype AcDEF; the other four (rough) strains were of full biotype 11 bdef and resistotype $\mathrm{AcDeFH}$, or similar types (table II).

None of the P-fimbriate AD strains was haemolytic.

\section{Discussion}

Biochemically inactive strains of $E$. coli, formerly called AD, merit no special taxonomic position nowadays (Farmer et al., 1985), being distributed instead among appropriately specified $E$. coli $\mathrm{O}$ serogroups (Kauffmann, 1969; Edwards and Ewing, 1972). For example, strains of AD serogroup $\mathrm{O} 1$ contain the same $\mathrm{O}$ antigens as $E$. coli $\mathrm{O} 1$ (Frantzen, 1950). The 18 strains of AD serogroup O1 examined by us were anaerogenic, non-haemolytic, non-motile (and $\mathrm{H}^{-}$), $\mathrm{P}$ fimbriate and generally type-1 non-fimbriate. Furthermore, all belonged to primary biotype 11 and to closely related full biotypes. Yet, among 599 biochemically active strains of $E$. coli previously described, many of them of urinary origin (Crichton and Old, 1982), the unusual combination of secondary biotype characters (bcdef) was never found among strains of primary biotype 11 which itself was uncommon
(Crichton and Old, 1982). The observed stability of the biotype-resistotype profiles of the AD strains of serogroup $\mathrm{Ol}$ was all the more remarkable because they had been isolated from different countries in North America and Scandinavia and from the UK over more than 60 years and it seems likely that they belong to a clone with a long history. Furthermore, the finding that four other P-fimbriate, rough AD strains were also of full biotype $11 \mathrm{bdef}$ and of resistotypes similar to AcDeFH suggested that they too might be related to the serotypable strains of serogroup 01 .

Among a total of 55 strains of $E$. coli of serotype $01: \mathrm{Kl}$ isolated in Europe and USA, two clones were identified that had a distinct outer-membraneprotein (omp) pattern and biotype and were thought to be of independent origin (Achtman et al., 1983; Ørskov and Ørskov, 1983). VäisänenRhen et al. (1984) by definition of full serotype, omp pattern, adhesins and haemolysin production recognised seven major pyelonephritogenic clones of $E$. coli and showed similarly that one particular omp pattern was predominant among strains of serotype $\mathrm{O} 1: \mathrm{K} 1: \mathrm{H} 7$ but that another omp pattern was associated with $\mathrm{O} 1$ strains of faecal origin. Whereas the former (consisting of two subclones different in type-1 fimbriation) were $P$ fimbriate, the latter were generally $P$ non-fimbriate (VäisänenRhen et al., 1984).

Many of our AD strains of serogroup O1 possessed $\mathrm{K} 1$ antigen though that information was not available for all of them. It is important, therefore, to establish whether these AD strains belong to previously described clones of serotype O1:K1. AD strains of serogroup O1, though similar to the nonmotile strains of omp-pattern 5 of Achtman et al. (1983) in not requiring nicotinamide for growth, differed from them in three important biotype characters (indole, dulcitol, rhamnose). The AD strains of serotype $\mathrm{Ol}$ also differed from the generally motile strains of the pyelonephritogenic clone of serotype $\mathrm{O} 1: \mathrm{K} 1: \mathrm{H} 7$ in four biotype characters (ornithine, nicotinamide requirement, rhamnose, salicin) of the nine characters described by Achtman et al. (1983). Thus, although we did not perform omp analysis, the overall properties of $\mathrm{AD}$ strains of serogroup $\mathrm{O} 1$ seem to distinguish them from the two O1 clones of Achtman et al. (1983) and Väisänen-Rhen et al. (1984).

$\mathrm{AD}$ serogroup $\mathrm{O} 2$ is closely related, but not identical, to $E$. coli $O$ group 25 (Frantzen, 1950) among which P-fimbriate clones have not been described (Ørskov et al., 1982; Väisänen-Rhen et al., 1984). Thus, the P-fimbriate strains of serogroup $\mathrm{O} 2$ examined here, isolated in different 
countries over more than 35 years, may represent yet another P-fimbriate clone, members of which are non-motile (and $\mathrm{H}^{-}$), anaerogenic, non-haemolytic and belong to closely related biotypes and resistotypes. AD serogroup $\mathrm{O} 2$ is also related, though poorly, to other $E$. coli $\mathrm{O}$ serogroups including O16, 19 and 68 (Frantzen, 1950; Kauffmann, 1969; Edwards and Ewing, 1972). Any relationship, therefore, between P-fimbriate strains of $\mathrm{AD}$ serogroup $\mathrm{O} 2$ and some of these latter types, though unlikely, should be investigated.

It was of particular interest that the AD strains identified as $\mathbf{P}$ fimbriate in our tests with $\bar{p}$ erythrocytes and HCF reacted only weakly, or not at all, in slide-agglutination tests with pure P-fimbrial antisera. These findings illustrate yet again the antigenic heterogeneity existing among $P$ fimbriae and extend the results of Rhen et al. (1983) who, by ELISA testing, demonstrated major differences in crossreactivity among $\mathbf{P}$ fimbriae of different pyelonephritogenic isolates of $E$. coli. The minor differences shown here among AD strains of serogroups $\mathrm{O} 1$ and $\mathrm{O} 2$ with absorbed P-fimbrial antisera may reflect quantitative variation in $\mathrm{P}$-antigen production.

The consistent, albeit weak, agglutination of guinea-pig erythrocytes shown by only three of the P-fimbriate AD strains has also been noted for a few other P-fimbriate strains of $E$. coli of urinary origin (Crichton, 1980; Källenius et al., 1980 $a$ and $b$ ). The inhibition of that (guinea-pig) MREHA reaction by HCF showed its association with $P$ fimbriation and extends the findings of Parry et al. (1984) who similarly demonstrated the P-specific haemagglutination of sheep, pigeon and chicken erythrocytes.

In this study, the clinical information available to us was in many cases insufficient to establish

\section{REFERENCES}

Achtman M et al. 1983 Six widespread bacterial clones among Escherichia coli $\mathrm{K} 1$ isolates. Infection and Immunity 39:315335.

Adegbola R A, Old D C 1982 New fimbrial hemagglutinin in Serratia species. Infection and Immunity 38:306-315.

Bamforth J 1934 An enquiry into the Coli Anaerogenes bacteria. Journal of Hygiene 34:69-80.

Crichton P B 1980 Differential typing of Escherichia coli strains. $\mathrm{PhD}$ thesis, University of Dundee.

Crichton P B, Old D C 1979 Biotyping of Escherichia coli. Journal of Medical Microbiology 12:473-486.

Crichton P B, Old D C 1982 A biotyping scheme for the subspecific discrimination of Escherichia coli. Journal of Medical Microbiology 15:233-242.

Crichton P B, Old D C 1983 Characterization of Escherichia coli strains from long-term urinary tract infections by combined typing techniques. Journal of Urology 129:160-162. whether the AD strains had been associated with pyelonephritis or even with urinary-tract infection. Furthermore, when in the past AD bacteria were considered as distinct entities, it was interest in their biochemical and serological relationships to shigellae and their possible role in gastroenteritis that attracted attention (Frantzen, 1950; Edwards and Ewing, 1972). Nevertheless, several early studies provide enough evidence to show that Alkalescens bacteria were responsible for a not inconsiderable number of infections of the urinary tract and often for pyelonephritis (Bamforth, 1934; Neter and Heide, 1940; Weil, 1943).

The need to identify clones of $E$. coli in human infection is important for pinpointing their likely virulence determinants. It also draws attention to previously overlooked and yet distinctive groups, such as the two P-fimbriate clones of E. coli, of wide geographic distribution and historic lineage that are here described. Though typing of $E$. coli by observations of many different phenotypic characters is sufficient to indicate in the short term probable clonal relationships, it is insufficient to demonstrate clonal disseminations that have taken place over long periods, especially when there has been divergence in their phenotypic markers. To answer the question as to which types of strains isolated from different sources today might many years ago have descended from a common ancestral bacterium, i.e., are members of a clone, evidence of genetic homo$\operatorname{logy}$ is required but for the P-fimbriate strains of $E$. coli this has yet to be demonstrated.

We thank Drs G. Källenius, F. Ørskov, I. Ørskov and B. Rowe for gifts of strains and information about them. We are also indebted to Dr D. Tovey for $\bar{p}$ erythrocytes and Dr H. Williams for generous supplies of hydatid-cyst fluid.

Crichton P B, Old D C 1985 Biotyping of Escherichia coli: methods and applications. In: Sussman M (ed) The virulence of Escherichia coli: reviews and methods. Academic Press, Orlando, FL, pp 315-332.

Crichton P B, Ip S M, Old D C 1981 Hemagglutinin typing as an aid in identification of biochemically atypical Escherichia coli strains. Journal of Clinical Microbiology 14:599-603.

Duguid J P, Clegg S, Wilson M I 1979 The fimbrial and nonfimbrial haemagglutinins of Escherichia coli. Journal of Medical Microbiology 12:213-227.

Edwards P R, Ewing W H 1972 Identification of Enterobacteriaceae, 3rd edn. Burgess Publishing Co., Minneapolis, pp 98 100.

Elek S D, Higney L 1970 Resistogram typing-a new epidemiological tool: application to Escherichia coli. Journal of Medical Microbiology 3:103-110.

Farmer J J et al. 1985 Biochemical identification of new species and biogroups of Enterobacteriaceae isolated from clinical specimens. Journal of Clinical Microbiology 21:46-76. 
Frantzen E 1950 Biochemical and serological studies on alkalescens and dispar strains. Acta Pathologica et Microbiologica Scandinavica 27:236-248.

Källenius G, Möllby R 1979 Adhesion of Escherichia coli to human periurethral cells correlated to mannose-resistant agglutination of human erythrocytes. FEMS Microbiology Letters 5:295-299.

Källenius G, Möllby R, Svenson S B, Winberg J, Hultberg H $1980 a$ Identification of a carbohydrate receptor recognized by uropathogenic Escherichia coli. Infection, suppl. 3:288293.

Källenius G et al. $1980 b$ The $\mathbf{P}^{k}$ antigen as receptor for the haemagglutinin of pyelonephritic Escherichia coli. FEMS Microbiology Letters 7:297-302.

Källenius G et al. 1981 Occurrence of P-fimbriated Escherichia coli in urinary tract infections. Lancet 2:1369-1372.

Kauffmann F 1969 The bacteriology of Enterobacteriaceae, 2nd edn. Munksgaard, Copenhagen, pp 43-45.

Neter E, Heide A M 1940 Pathogenicity, biochemical characters and antigenic structure of Shigella alkalescens Andrewes. American Journal of Hygiene 31B:69-73.

Old D C 1985 Haemagglutination methods in the study of Escherichia coli. In: Sussman M (ed) The virulence of Escherichia coli: reviews and methods. Academic Press, Orlando, FA, pp 287-313.

Old D C, Crichton P B, Maunder A J, Wilson M I 1980 Discrimination of urinary strains of Escherichia coli by five typing methods. Journal of Medical Microbiology 13: 437444.

Ørskov I, Ørskov F, Birch-Andersen A, Kanamori M, Svanborg-Edén C $1982 \mathrm{O}, \mathrm{K}, \mathrm{H}$ and fimbrial antigens in Escherichia coli serotypes associated with pyelonephritis and cystitis. Scandinavian Journal of Infectious Diseases, suppl. 33:18-25.

Ørskov F, Ørskov I 1983 Summary of a workshop on the clone concept in the epidemiology, taxonomy and evolution of the Enterobacteriaceae and other bacteria. Journal of Infectious Diseases 148:346-357.

Ørskov I, Birch-Andersen A, Duguid J P, Stenderup J, Ørskov F 1985 An adhesive protein capsule of Escherichia coli. Infection and Immunity 47:191-200.

Parry S H, Rooke D M, Sussman M 1984 Analysis of mannoseresistant adhesins of Escherichia coli by a naturally occurring glycoprotein receptor analogue. Journal of Microbiological Methods 2:323-331.

Rhen M, Klemm P, Wahlström E, Svenson S B, Källenius G, Korhonen T K 1983 P-fimbriae of Escherichia coli: immuno- and protein-chemical characterization of fimbriae from two pyelonephritogenic strains. FEMS Microbiology Letters 18:233-238.

Väisänen V et al. 1981 Mannose-resistant haemagglutination and $P$ antigen recognition are characteristic of Escherichia coli causing primary pyelonephritis. Lancet 2:1366-1369.

Väisänen V, Korhonen T K, Jokinen M, Gahmberg C G, Ehnholm C 1982 Blood group $M$ specific haemagglutinin in pyelonephritogenic Escherichia coli. Lancet 1:1192.

Väisänen-Rhen et al. 1984 P-fimbriated clones among uropathogenic Escherichia coli strains. Infection and Immunity 43:149-155.

Weil A J 1943 Progress in the study of bacillary dysentery. Journal of Immunology 46:13-46.

Williams P H, Knutton S, Brown M G M, Candy D C A, McNeish A S 1984 Characterization of nonfimbrial mannose-resistant protein hemagglutinins of two Escherichia coli strains isolated from infants with enteritis. Infection and Immunity 44:592-598.

Wilson M I, Crichton P B, Old D C 1981 Characterisation of urinary isolates of Escherichia coli by multiple typing: a retrospective analysis. Journal of Clinical Pathology 34:424428. 